\title{
EDUCAÇÃO PARA INTEIREZA E AMBIENTALIZAÇÃO CURRICULAR: DIÁLOGOS NECESSÁRIOS SOBRE MATRIZES CURRICULARES DOS CURSOS DE GRADUAÇÃO
}

Izabel Cristina Feijó de Andrade ${ }^{1}$ Marina Patrício de Arruda ${ }^{2}$

Lucia Ceccato Lima ${ }^{3}$

Resumo: O objetivo desse estudo foi identificar indícios de ambientalização por meio da análise dos documentos curriculares e ementas das disciplinas dos cursos de graduação de uma Universidade Comunitária do interior de Santa Catarina. Para as análises fez-se uso do software para análises qualitativas MAXQDA ${ }^{\mathrm{TM}}$. O exposto permitiu detectar o caminho, até então, percorrido por essa instituição de ensino para a inserção do tema educação ambiental em documentos curriculares. Observamos após esse breve estudo que na sociedade como na Universidade, a Educação Ambiental diz respeito a um processo que inclui debates, reforma de pensamento e participação dos vários processos de ensino, pesquisa, extensão e gestão nas questões de meio ambiente.

Palavras-chave: Ambientalização Curricular; Educação para Inteireza; Matrizes Curriculares; Cursos de Graduação;

${ }^{1}$ Bolsista do Pós-Doc do PPGE/UNIPLAC Dra em Educação/PUCRS. E-mail: andrade@technologist.com

2 Professora o PPGE e PPGAS/ UNIPLAC E-mail: marininh@terra.com.br

3 Professora o PPGE e PPGAS/ UNIPLAC. E-mail: prof.lucia@uniplaclages.edu.br 


\section{Introdução}

O diálogo entre Educação para Inteireza e Ambientalização Curricular se faz necessário tendo em vista a necessidade de implementação efetiva da Educação Ambiental (EA) nas Instituições de Ensino Superior (IES) e a formação de educadores ambientais. O objetivo desse estudo foi identificar indícios de ambientalização por meio da análise dos documentos curriculares; ementas das disciplinas dos cursos de graduação de uma Universidade Comunitária do interior de SC. A partir da experiência vivenciada num projeto interinstitucional sobre ambientalização ${ }^{4}$, pesquisa que foi desenvolvida em 2017 de forma concomitante por pesquisadores de oito Instituições de Educação Superior (IES), uma pública e sete comunitárias, localizadas em cinco mesorregiões de Santa Catarina, nos sentimos instigados a tal construção de conhecimento.

Frente a essa articulação interinstitucional nossa Universidade assumiu importante papel na discussão sobre formação e responsabilidade socioambiental. Partimos do pressuposto de que a crise ambiental e a necessidade de sensibilização, participação e socialização de conhecimentos produzidos tornaram-se urgentes para minimização dos impactos das mudanças climáticas que afetam nosso Estado, o país e o planeta, e dos ônus causados pela degradação ambiental pela exploração desenfreada da biodiversidade.

Para tanto, os conceitos de Ambientalização e Educação para Inteireza, que já vinham sendo discutidos pela Universidade por meio de alguns projetos de extensão, ganham força, especialmente, com a Resolução nº 2/2012 do Conselho Nacional de Educação Ambiental, que estabeleceu Diretrizes Curriculares Nacionais para a educação Ambiental (EA) determinando que aos sistemas de ensino promovessem condições para que as instituições educacionais se constituam em:

[...] espaços educadores sustentáveis, com a intencionalidade de educar para a sustentabilidade socioambiental de suas comunidades, integrando currículos, gestão e edificações, em relação equilibrada com 0 meio ambiente e tornando-se referência para seu território (BRASIL, 2012, p. 7).

Mas, como promover conhecimentos concernentes à Educação Ambiental nos currículos da Educação Superior se os educadores ainda não se encontram preparados para esse compromisso? Como reformar o pensamento

\footnotetext{
${ }^{4}$ Aprovado em chamada pública FAPESC № 01/2014 - Programa Universal, intitulado "AMBIENTALIZAÇÃO E SUSTENTABILIDADE NA EDUCAÇÃO SUPERIOR: SUBSÍDIOS ÀS POLÍTICAS INSTITUCIONAIS EM SANTA CATARINA" , o projeto tem por objetivo contribuir com as Políticas de ambientalização e sustentabilidade na Educação Superior em Santa Catarina, esta investigação busca identificar indícios, elaborando subsídios e estratégias aplicáveis ao ensino, pesquisa, extensão e gestão ambiental nessas Instituições.
}

revista brasileira educação ambiental 
rumo à Ambientalização Curricular? Como promover a articulação das ações educativas voltadas às atividades de proteção, recuperação e melhoria socioambiental potencializando a função da educação para as mudanças culturais e sociais relacionadas à educação ambiental (EA)?

Assim, a educação brasileira se vê desafiada a responder a desafios contemporâneos complexos cujas implicações para a atuação do educador incidem sobre novas perspectivas teóricas e metodológicas. Nesse sentido, o diálogo que aqui se estabelece relaciona-se à necessidade de se criar possibilidades para uma mudança e reforma de pensamento (MORIN, 2010) de educadores do Ensino Superior.

Essa proposta demanda um esforço de complexidade pessoal e institucional por envolver a articulação de diferentes espaços como ensino, pesquisa, extensão e gestão como instâncias responsáveis pela formação dos futuros profissionais. Reconhecendo o compromisso e responsabilidade da Universidade em relação ao processo de formação de educadores ambientais, propomos uma reflexão que relaciona Ambientalização Curricular e Educação de inteireza tendo em vista nossa preocupação em considerar as várias dimensões do ser humano, cuja relação com o ambiente traz consequências para a vida do planeta.

[...] ideia de inteireza entendida na construção do conhecimento não resultante apenas de experiências trazidas de fora para dentro, de exigências externas individuais ou coletivas, mas também de dentro para fora, da essência do próprio educador, a partir de seus interesses, necessidades, valores, imaginação, intuição, crenças, saberes, vinculando-se à sua própria existencialidade (ANDRADE; PORTAL, 2015, p.1)

O que se deseja não é somente discutir a necessidade da Educação Ambiental, mas que os processos educativos contemplem os sujeitos na sua integralidade, transcendendo os conceitos técnicos da EA para uma perspectiva individual (eu), comportamental (ações do eu), cultural (valores internalizados e que se manifestam no individual/comportamental), social (como organizamos socialmente os valores individual, comportamental, cultural) e espiritualmente (que se manifesta na inter-relação entre as funções e pensar, sentir, agir integralmente no mundo).

Todos esses processos são complementares e dão sentido às ações e relações estabelecidas com os outros e com 0 ambiente marcando, conscientemente, a história da própria espécie humana no planeta. Portanto, buscamos em Morin (2015, p.20) base para compreender que "no mundo humano, o desenvolvimento da inteligência é inseparável do mundo da afetividade".

Nos dias atuais intensificam-se discussões acadêmicas sobre a necessidade de se prestigiar as abordagens que considerem o pensamento complexo, o caos organizador, as estruturas assimétricas, as diferentes 
realidades, as incertezas e provisoriedades da vida. Assim, não basta ter clareza sobre visões de mundo segmentadas ou sobre propostas de universidades marcadas pela simplificação e fragmentação das disciplinas, é preciso assumir o compromisso de rever o próprio modo de pensar, de significar e de agir como sujeitos de inteireza, aquele capaz de contribuir "para uma educação e cuidado humanos que incluam a si mesmo, o outro, o planeta e sua conexão com o Universo" (POZATTI, 2012).

Como alerta Morin (2015), estamos diante de problemas complexos que as sociedades contemporâneas criaram e só os estudos de caráter inter-politransdisciplinares ou integrais (individual, comportamental, cultural, social e espiritual) poderiam nos orientar nas análises de tais complexidades: "Afinal, de que serviriam todos os saberes parciais senão para formar uma configuração que responda a nossas expectativas, nossos desejos, nossas interrogações cognitivas?' (p.16).

A ação humana incide sobre a questão ambiental e a EA surge como uma estratégia educacional capaz de "reformar o pensamento" das pessoas para o cuidado consigo mesmas, com o outro e com a natureza. "Este novo entrelaçar entre a natureza e a humanidade necessitará, sem dúvida, como acabamos de dizer, de uma superação da técnica atual que, por sua vez, necessita de uma superação do modo de pensar atual, inclusive o científico" (MORIN, 2010; p.94). A crise ambiental compreendida como uma crise da racionalidade instrumental (LEFF, 2001) segue espalhando seus efeitos sobre o ambiente natural, em relação à preservação da vida e da biodiversidade, ameaçadas pelo modelo capitalista de produção, consumo e descarte.

Em 2002, no Fórum Global para o Desenvolvimento Sustentável (DS), realizado em Johanesburgo, África do Sul, foi proposta a Proclamação da Década Internacional de Educação para o Desenvolvimento Sustentável (DEDS).

Segundo a Organização das Nações Unidas para a Educação, Ciência e Cultura (UNESCO), a promoção da DEDS se dará especificamente no estabelecimento de padrões de qualidade para a educação voltada ao desenvolvimento sustentável, considerando a inteireza do ser a partir das dimensões ambiental, econômica e de justiça social como objetivos a serem alcançados para as gerações atuais e as futuras. Espera-se que esse esforço educacional possa criar incentivos para mudanças individuais, comportamentais e culturais que serão desdobradas em um futuro mais sustentável (UNESCO, 2012).

A resistência inicial observada é própria ao desconhecimento de uma proposta relativamente recente como o programa supracitado e indica a necessidade de outras aproximações e discussões. Para as análises foi utilizado o software para análises qualitativas MAXQDA ${ }^{\mathrm{TM}}$. Esse programa auxilia o pesquisador no processo de localização e marcação do conteúdo, destacando-se pela facilidade no tratamento dos dados e na apresentação de novas visões das informações recolhidas pelo pesquisador. Nesse sentido, o

revista brasileira educação ambiental 
investigador é o principal instrumento de análise dos dados, auxiliado por uma ferramenta informatizada.

Nesse contexto, a universidade como instituição promotora e formadora de educadores, apresenta-se como espaço importante na consolidação de uma nova proposição de desenvolvimento sustentável e de inteireza do ser.

\section{Educação para inteireza e ambientalização curricular}

Embora esses dois conceitos sejam bastante recentes, sobretudo no que se refere à formação de professores, temos percebido um compromisso de alguns estudiosos como Morin (2001), Capra (2002) e Maturana (2002), em evidenciarem a necessidade de discussões sobre orientações curriculares mais amplas e inovadoras, especialmente, quanto relacionadas à questão ambiental.

Os conceitos de Educação para Inteireza e de Ambientalização Curricular considerados como interdependentes e complementares incluem várias dimensões do humano e demandam uma visão sistêmica sobre as relações entre ambiente e a vida do planeta.

A Educação para Inteireza surge como uma orientação integral ou uma forma de conhecimento do ser humano ao integrar várias dimensões sejam elas espiritual, ambiental, emocional, física ou cognitiva. Uma educação que transcende a visão mecanicista, antropocêntrica e materialista integrando-as numa dimensão superior de maior complexidade (MARTINELLI, 1996). Mas de acordo com esse pensamento, para que essa mudança se efetive, torna-se necessário articular outras ciências, artes e escolas de filosofia, procurando saberes fronteiriços que integrem diferentes pensamentos. A implicação desta integração pode nos levar a uma educação transdisciplinar e holística. Seria a busca de caminhos e possibilidades para que o ser humano possa expandir sua consciência rumo à qualidade de vida da realidade humana.

A consciência da responsabilidade dos nós docentes na Educação Ambiental dependerá do grau de reflexão e de ampliação de nossa consciência, pois estamos diante de "[...] uma encruzilhada: continuar refletindo no espelho o materialismo científico, o pluralismo fragmentário e o pósmodernismo desconstrucionista, ou olhar para além do espelho escolhendo uma vereda mais integral, mais abrangente e mais inclusiva" (WILBER, 2007, p. 11) e sustentável.

Essa escolha, por nós assumida, passou a exigir uma reflexão no sentido de repensar a caminhada numa dimensão do educador ambiental a partir da sustentabilidade, ou seja, dos aspectos humanos que compõem a sua inteireza.

Nessa perspectiva de conexão corpo-mente-coração-espírito, Portal (2012) afirma que o desenvolvimento da inteireza, desafia a produção científica e a exigência legal da educação nas Instituições de Educação Superior que se apresentam frágeis e "quase nada vem contribuindo para que o ser humano possa encontrar-se, constituir relações sociais e ambientais passíveis de 
reconciliação de si e, consequentemente, da sociedade" (p.2). O campo está aberto ao novo. Alguns avanços teóricos e práticos apontam para a possibilidade de se assumir a complexidade da educação ambiental na busca da inteireza do ser (ANDRADE, 2011; ANDRADE; PORTAL, 2015).

Transcender para perto da transdisciplinaridade de Basarab Nicolescu (2000) ou do sentido da complexidade de Edgar Morin (2010), num realismo consciente, provocando uma ampliação da consciência e exigindo mudança de atitude ambiental é o caminho da ambientalização curricular que, como um novo conhecimento, desafia universidades e professores.

Segundo a Política Nacional de Educação Ambiental, no ensino superior é facultada a criação de disciplinas nas áreas voltadas aos aspectos metodológicos da Educação Ambiental (EA), nos cursos de pós-graduação e de extensão (ZUIN; FREITAS, 2007).

Assim, o olhar ampliado para a educação do século XXI nos faz refletir sobre a importância do educar-se por inteiro, e de se empenhar pela integração de disciplinas, de modo a unir perspectivas até então excludentes para então transcender à fragmentação que adotamos por hábitos baseados numa percepção de mundo reducionista.

Para o conceito de ambientalização curricular buscamos nos orientar em Oliveira e Freitas (2004, p.166) também numa perspectiva transdisciplinar alimentada por "aspectos tanto conceituais, como procedimentais, atitudinais e políticos, envolvendo aspectos cognitivos, emocionais e valorativos relativos à temática ambiental". Nesse contexto complexo de percepção de mundo, encontramo-nos por inteiro.

Utilizado por Japiassu (2006), Morin (2003), Portal (2006) e Wilber (2007) o termo inteireza diz respeito à "Qualidade do que é inteiro", portanto, a educação não pode mais seguir fragmentada produzindo consciências reducionistas e desprezando as mais variadas dimensões humanas em nome de uma ciência que priorizou a parte em detrimento do todo.

No sentido da Educação para inteireza é que buscamos compreender a ambientalização curricular como caminho propício à institucionalização da educação ambiental (EA). A ambientalização curricular entendida como "[...] um processo de inovação que realiza mudanças no currículo por meio de intervenções que visam integrar temas socioambientais aos seus conteúdos e práticas" (KITZMANN; ASMUS, 2012, p. 270).

A Educação para a Inteireza sinaliza a importância de se integrar alma, coração e razão (PORTAL, 2006) contribuindo com as propostas do pensamento complexo de Edgar Morin (2000) no qual o homem é, ao mesmo tempo, razão e emoção. Assim, se configura "uma proposta de autoconstrução do Ser Humano" cujas dimensões constitutivas básicas são sociais, emocionais, espirituais e racionais, que desenvolvidas de forma equilibrada são

revista brasileira educação ambiental 
essenciais para a ressignificação de sua dignidade (PORTAL, 2006, p. 77) e da dignidade planetária. Esses elementos próprios da natureza humana articulados num todo complexus de vivências e de experiências da vida do educador do Ensino Superior.

Nesse contexto de complexidade, a IES compreendida como instância de ensino, pesquisa e extensão necessita de renovação mais radical, aquela que talvez não tenha ainda sido enfrentada: A reforma do pensamento para que possa desenvolver "valores que dignifiquem a vida e se sustentem em uma ética de dimensões planetárias" (TESCAROLO; DARÓS, 2007, p.139). O pensamento multidimensional, inclusivo e integrador "capaz de compreender a complexidade do real e construir um conhecimento que leve em consideração essa mesma amplitude" (MORAES, 1998, p.30). A busca por processos pedagógicos transformadores em que a "aprendizagem passa a ter foco na visão complexa do universo e na educação para vida" (BEHRENS, 2006, p.14).

Educar é também viver sendo necessário "responsabilizarmo-nos pelo projeto do nosso crescimento, tornando-nos sujeitos/agentes transformadores, criadores e diretores do nosso próprio projeto de vida", conforme nos orienta Portal (2004, p.116).

Assim sendo, o enfoque da Ambientalização Curricular se abre à Educação para a Inteireza firmando novos compromissos para a formação de professores e ensino superior. Mas afinal, qual é o lugar da educação ambiental nos currículos do ensino superior? Por onde começar a reforma?

[...] chegamos a um impasse: não se pode reformar a instituição sem uma prévia reforma das mentes, mas não se podem reformar as mentes sem uma prévia reforma das instituições. Essa é uma impossibilidade lógica que produz um duplo bloqueio (MORIN, 2000, p.99).

Caberá aos educadores o protagonismo dessa mudança rompendo com esse duplo bloqueio?

\section{Diálogos necessários sobre matrizes curriculares}

As pesquisas sobre a Ambientalização Curricular vêm se constituindo em um campo profícuo de investigação. ,Assim, identificar indícios de ambientalização na Educação Superior se impõe como compromisso. Começamos esse estudo pelas ementas de todos os cursos de graduação de uma universidade comunitária perseguindo vislumbrar possibilidades de ambientalizar a matriz curricular. Para Godoy (2012, p. 251):

Os processos de ambientalização curricular, ambientalização institucional, ambientalização da educação e ambientalização da sociedade, através dos quais é reconfigurado o estatuto profissional, a pesquisa e o ensino, articulam o jogo entre a 
delimitação do campo de experiência e a definição de normas de conduta a partir do investimento no conhecimento prospectivo: na capacidade de cada um para extrair informação, se produzir como informação e comunicar dados em proveito de inovações.

Nessa perspectiva, organizamos um quadro geral com cursos, disciplinas e ementas que relacionavam a educação ambiental. No Quadro 1 abaixo, especificamente, separamos os vários cursos cujas ementas de disciplinas que ainda não investem na ambientalização curricular:

Quadro 1: Cursos sem indícios de Ambientalização Curricular

\begin{tabular}{|ll|}
\hline 1. & Artes Visuais \\
\hline 2. & Ciências Contábeis \\
\hline 3. & Educação Especial FUNDES \\
\hline 4. & Educação Física \\
\hline 5. & Fisioterapia \\
\hline 6. & Jornalismo \\
\hline 7. & Letras: Língua Portuguesa e Língua Espanhola \\
\hline 8. & Letras: Língua Portuguesa e Língua Inglesa \\
\hline 9. & Matemática \\
\hline 10. Medicina \\
\hline 11. Música \\
\hline 12. Odontologia \\
\hline 13. Sistemas de Informação \\
\hline 14. Tecnologia em Cosmetologia e Estética \\
\hline 15. Tecnologia em Design de Interiores \\
\hline
\end{tabular}

Fonte: site da referida Universidade. Elaborado pelas autoras, 2017.

Isso pode ocorrer, pois é necessária uma mudança significativa na forma como pensamos e agimos. Morin propõe uma reforma do pensamento para a formação de cidadãos planetários, solidários e éticos. Dessa forma, é necessário compreender a condição humana para "nos ajudar a viver um modo de pensar aberto e livre" (MORIN, 2004, p.11). O conhecimento fragmentado nos impede à visão do todo e os problemas essenciais nunca são parceláveis, são problemas globais e, cada vez mais, essenciais (MORIN, 2004). Situamos o pensamento complexo como fundamento à compreensão das relações inerentes às coisas e ao "tecido junto" que sustenta o universo, considerando que Morin (2004, p.184) aponta:

A reforma do conhecimento exige a reforma do pensamento. A reforma do pensamento exige que um pensamento que possa religar os conhecimentos entre si, religar as partes ao todo, o todo as partes e que possa conceber a relação do global com o local, do local com o global. Nossos modos de pensar devem integrar um vaivém constante entre esses níveis [...] 
Como apontado acima, as instituições também vivem essa fragmentação, compartimentalização do conhecimento no e entre o ensino, a pesquisa, a extensão e a gestão em diversos aspectos. A pesquisa realizada nos permitiu identificar como a dimensão ambiental perpassa 0 fazer universitário, ou seja, permeando processos e pensamentos.

A "fragmentação das disciplinas" é um ponto preocupante quando se parte do entendimento de que ambientalização é um ponto de mudança paradigmática para a Universidade do século XXI. Tradicionalmente, os currículos foram construídos sob o enfoque mecanicista e simplificador, pois o ser humano, por muitos anos, foi concebido a partir de partes/fragmentos/pedaços. No entanto, novos paradigmas em educação indicam a religação de saberes (MORIN, 2000) como processo essencial à vida dos seres vivos e do ambiente.

Nesse sentido, a questão da ambientalização, por sua vez, surge como uma ação estratégica para a "reforma do pensamento" das pessoas para o cuidado consigo, com o outro e com a natureza. A crise ambiental compreendida como crise da racionalidade instrumental segue espalhando seus efeitos sobre o ambiente natural, sobre a vida do planeta ameaçada pelo modelo capitalista de produção, consumo e descarte. Ambientalização, como outros processos socioculturais, implicam transformar o comportamento das pessoas.

Seguimos analisando as estruturas curriculares para a composição de quadros que destacassem cursos cujas ementas de disciplinas relacionassem à temática ambiental. No curso de Administração, conforme destacamos no Quadro 2, observamos uma maior quantidade de ementas de disciplinas que contemplam a questão da Educação Ambiental. Nesse rol de disciplinas, temas variados são contemplados e permitem discussão mais ampla sobre compromisso da universidade e questões ambientais. No caso do Curso de Administração, observamos que a partir da oferta dessas disciplinas, chamam atenção sobre o modelo de gestão sem responsabilidade ambiental tanto de gestores como de consumidores.

Quadro 2: Curso com indícios de Ambientalização Curricular.

\begin{tabular}{|l|c|}
\hline Curso de & $\checkmark$ Administração Ambiental \\
Administração & $\checkmark$ Contabilidade Social \\
& $\checkmark$ Direito Empresarial \\
& $\checkmark$ Desenvolvimento e Administração de \\
& $\checkmark$ Novos Empreendimentos \\
& $\checkmark$ Gestão Ambiental \\
& $\checkmark$ Administração Ambiental \\
\hline
\end{tabular}

Fonte: Elaborado pelas pesquisadoras, 2017. 
al. (2000) ainda há dificuldades de alinhamento da visão entre estudantes e empresários, em razão da centralidade dos objetivos empresariais. No entanto, algumas ementas já investem na formação de outra mentalidade em relação a esse tipo de situação. O estudo de Gonçalves-Dias et al. (2006) defende que ao inserir a gestão ambiental no universo do curso de graduação em Administração amplia-se a dimensão ecológica do comportamento de futuros administradores possibilitando reflexões sobre as condições, os desafios e as perspectivas para a ampliação da educação socioambiental.

Das disciplinas elencadas no curso de Administração pudemos extrair temas como: Desenvolvimento sustentável. Empresa e meio ambiente. Ecobusiness. Ecoestratégia nas empresas. Sistemas de gestão ambiental. Avaliação dos efeitos ambientais. Gestão ambiental pública. Política de proteção ao meio-ambiente. Ecologia e meio ambiente. Relação com o meio ambiente. Empresa e meio ambiente. Sistema de gestão ambiental: recursos e problemas. Responsabilidade socioambiental das organizações e o desenvolvimento sustentável. Questões ambientais no Brasil: licenciamento ambiental; auditoria ambiental.

Para Kitzmann (2007), ambientalizar significa inserir a dimensão socioambiental ou está tratada de forma inadequada, não podendo estar baseado em ações fragmentadas e pontuais. Assim, constitui-se como um compromisso institucional e demanda mudanças administrativas e estruturais para que seja efetivado.

Ambientalização como processo de internalização nas práticas voltadas ao cuidado com o ambiente e aspectos ambientais (CARVALHO; TONIOL, 2010) diz respeito à reforma do pensamento que almejamos para a Educação do futuro e mundo que habitamos.

Um novo sistema de educação fundado na religação e, por isso, radicalmente diferente do atual, deveria substituí-lo. Esse sistema permitiria favorecer a capacidade da mente para pensar os problemas individuais e coletivos em sua complexidade. Ele sensibilizaria para a ambiguidade, as ambivalências, e ensinaria a associar os termos antagônicos para apreender uma complexidade (MORIN, 2013, p.193).

A ambientalização curricular se apresenta como uma perspectiva de educação que contemple a abertura necessária à reforma do pensamento como multidimensional e interdisciplinar. Oliveira e Freitas (2004) destacam a interdisciplinaridade da ambientalização por considerarem conceitos, procedimentos, atitudes e políticas, bem como aspectos cognitivos, afetivos e valorativos da questão ambiental. Esse é também um dos conceitos utilizados 
pelos grupos de trabalho da rede Ambientalização Curricular no Ensino Superior - ACES 5 e destacado por Junyent, Geli e Arbat (2003).

O curso de Arquitetura e Urbanismo apresenta apenas uma disciplina que discute a questão ambiental e que diz respeito ao Conforto Ambiental. Nesse sentido, necessita ampliar essa discussão de modo a fortalecer competências profissionais de planejamento, implementação e avaliação de processos abrindo-se à ambientalização curricular. Nesse curso destaca-se nas ementas temas como: Sustentabilidade Ambiental; Bio-climatismo e arquitetura; Meio ambiente e o conforto térmico na arquitetura e no urbanismo; Meios naturais e artificiais; Movimento aparente do sol; Movimento aparente do sol e o uso de proteções; Tipos de clima e a adequação arquitetônica e urbana; Diferenças de dilatações térmicas através das estruturas; Tipos de clima e a adequação arquitetônica; Ventilação natural.

Alertamos que algumas disciplinas dessas elencadas aparecem como "Fragmentações" que é um ponto preocupante quando se parte do entendimento de que ambientalização é um ponto de mudança paradigmática para a Universidade do século XXI. Tradicionalmente, os currículos foram construídos sob o enfoque mecanicista e simplificador, pois o ser humano por muitos anos foi concebido a partir de partes/fragmentos/pedaços. No entanto, novos paradigmas em educação indicam a religação de saberes (MORIN, 2000) como processo essencial à vida dos seres vivos e do ambiente.

O Curso de Biomedicina apresenta, também, apenas uma disciplina intitulada Ecologia Antrópica que destaca os temas: Importância da Ecologia; Noções de ecologia antrópica; Conceitos básicos; Cadeia Alimentar; Ecossistema; Biomas da terra; Recursos naturais; Educação ambiental; Desequilíbrio ecológico e poluição. Nessa mesma área, temos os cursos de Fisioterapia e Medicina que não apresentam disciplinas que associem a Educação ambiental nas ementas, o que nos pareceu complicado por se tratar de área da saúde.

Podemos observar que as Diretrizes Curriculares Nacionais para a Educação Ambiental, atendidas pelo Conselho Nacional de Educação (CNE, 2012), referendam princípios da Constituição Federal (CF) e da Lei 9.795 de abril de 1999 que estabeleceu a Política Nacional de Educação Ambiental que indicam às instituições de ensino promover:

[...] trabalho de comissões, grupos ou outras formas de atuação coletiva favoráveis à promoção de educação entre pares, para participação no planejamento, execução, avaliação e gestão de projetos de intervenção e ações de sustentabilidade socioambiental na instituição educacional e na comunidade,

\footnotetext{
${ }^{5} \mathrm{~A}$ Red ACES foi um projeto intercultural e interdisciplinar que envolveu 11 universidades da América Latina e Europa entre 2002-2004. Do Brasil participaram a UFSCar-Univ. Federal de São Carlos; UNESP-Rio Claro-Univ. Estadual Paulista, Campus Rio Claro; e a UNICAMP-Univ. Estadual de Campinas.
}

Revbea, São Paulo, V. 13, № 1: 240-261, 2018. 
com foco na prevenção de riscos, na proteção e preservação do meio ambiente e da saúde humana, e na construção de sociedades sustentáveis (BRASIL, 2012, p. 6)

As Diretrizes Curriculares Nacionais para a Educação Ambiental também estabelecem que:

Os sistemas de ensino devem promover as condições para que as instituições educacionais constituam-se em espaços educadores sustentáveis, com a intencionalidade de educar para a sustentabilidade socioambiental de suas comunidades, integrando currículos, gestão e edificações em relação equilibrada com o meio ambiente, tornando-se referência para seu território (BRASIL, 2012, p. 7)

Assim, alertamos que temos que avançar nos processos de intervenção nas práticas formativas na área da saúde com a finalidade de ensartar modificações no currículo dos cursos de modo a instigar que futuros profissionais a exercerem suas funções com o olhar atento nos aspectos ambientais.

No curso de Biologia existe a disciplina de "Ecologia Básica", que apresenta na ementa os temas; Reconhecimento da importância da Ecologia. Dos conceitos básicos de ecologia, da cadeia alimentar, de ecossistema, de biomas da terra, dos recursos naturais, de educação ambiental, de desequilíbrio ecológico e poluição. No entanto, percebemos que a fragmentação e a ênfase nos aspectos ambientais se põem de forma tradicional e desconectada.

Nesse ponto de vista, para que as instituições ensino superior sejam espaços de formação de educadores sustentáveis, é essencial que seja dada a devida importância para a estes profissionais para que possam atrelar aos conhecimentos científicos suas competências práticas e atitudinais: "[...] a Educação tem, como uma de suas finalidades, a preparação para o exercício da cidadania" (BRASIL, 2012, p. 1).

Nas Diretrizes Curriculares Nacionais para a Educação Ambiental (BRASIL, 2012), incluir-se ainda que:

Em conformidade com a Lei no 9.795, de 1999, reafirma-se que a Educação Ambiental é componente integrante, essencial e permanente da Educação Nacional, devendo estar presente, de forma articulada, nos níveis e modalidades da Educação Básica e da Educação Superior, para isso devendo as instituições de ensino promovê-la integradamente nos seus projetos institucionais e pedagógicos (p. 3) 
Na prática docente nos cursos de graduação, quanto mais domínio o formador tiver sobre o desenvolvimento sustentável, mais ele poderá fortalecer para mudanças de atitudes em relação à interação do homem na natureza.

No curso de Direito observamos que se propõe, por meio de uma formação ética e cidadã, reforçar o compromisso de desenvolver os conteúdos jurídicos voltados para o meio ambiente. Assim, mostra uma preocupação em estudar as leis ambientais na sua execução e fiscalização. Dentre as disciplinas de conteúdos relacionados com a temática ambiental estão o Direito Ambiental e Direito Ecológico e pertencem à área de formação com prioridade aos conteúdos éticos e políticos (Quadro 3).

Quadro 3: disciplinas do Curso de Direito relacionadas à Ambientalização Curricular.

\begin{tabular}{|c|l|}
\hline \multirow{5}{*}{ Direito } & $\begin{array}{l}\checkmark \quad \text { Direito Ambiental } \\
\text { Ecologia e meio ambiente. Direito Ambiental. Código Florestal e a produção das } \\
\text { florestas. Convenção sobre diversidade biológica. Lei 9.605/1998. Princípios } \\
\text { legais para a proteção ambiental e o desenvolvimento sustentável. O papel da } \\
\text { sociedade civil e os mecanismos de participação popular na proteção do } \\
\text { ambiente. O programa das Nações Unidas para o meio-ambiente. }\end{array}$ \\
\cline { 2 - 2 } & $\begin{array}{l}\text { Ecologia e meio ambiente. A crise. O movimento ecológico. Ecodesenvolvimento } \\
\text { e desenvolvimento sustentável. Direito Ambiental. Conceitos. Fontes. Princípios. } \\
\text { Campos de avaliação. O Direito e os recursos ambientais. Direito Ambiental } \\
\text { Brasileiro. Direito Ambiental Comparado. O Programa das Nações Unidas para o } \\
\text { Meio Ambiente - PNUMA. Princípios legais supranacionais para a proteção } \\
\text { ambiental o desenvolvimento sustentável. }\end{array}$ \\
\hline
\end{tabular}

Fonte: Elaborado pelas pesquisadoras, 2017.

Os conteúdos trabalhados referem-se à proteção e legislação ambiental e enfatizam a proteção judicial e administrativa relacionada aos crimes contra o meio-ambiente. Esse ponto articula-se, por exemplo, a projetos interdisciplinares entre os cursos de Direito e Administração proposto por esta Universidade. Além disso, essas duas disciplinas demonstram a preocupação do curso de Direito em estudar as leis ambientais na sua execução e fiscalização.

Constatou-se, nesta análise, que essas disciplinas não têm caráter interdisciplinar, porém devem ser discutidas transversalmente entre todas outras disciplinas e até mesmo nos demais cursos da universidade.

$O$ curso de Enfermagem tem trabalhado com as questões relacionadas à saúde coletiva tendo em vista os problemas sanitários e de atendimento à saúde da população em geral. As questões ambientais estão voltadas ao reconhecimento das políticas públicas voltadas à relação prevenção, gestão sanitária e meio ambiente. O que torna evidente as implicações relacionadas às questões ambientais e às questões de saneamento básico. No curso de Enfermagem detectamos o Quadro 4: 
Quadro 4: disciplinas do Curso de Enfermagem relacionadas à Ambientalização Curricular.

\begin{tabular}{|l|l|}
\hline \multirow{5}{*}{ Enfermagem } & $\begin{array}{c}\checkmark \quad \text { Enfermagem em Saúde Coletiva } \\
\text { Políticas públicas de saúde. Reforma sanitária. Sistema Único de Saúde. } \\
\text { Saneamento básico e ambiental e suas relações com a saúde. Atividades } \\
\text { Práticas Supervisionadas nos Serviços de Saúde. }\end{array}$ \\
\cline { 2 - 3 } & $\begin{array}{l}\checkmark \text { Saúde Ambiental } \\
\text { Introdução à história da saúde pública mundial e brasileira. Introdução à } \\
\text { Reforma Sanitária. Sistema Único de Saúde. Estratégias de sobrevivência à } \\
\text { população de baixa renda. O saneamento básico e ambiental e suas } \\
\text { relações com a saúde. Mecanismo de controle e erradicação de doenças } \\
\text { transmissíveis no meio urbano e rural. Abastecimento de água, destinação } \\
\text { final de dejetos humanos, lixo e limpeza pública nas áreas urbanas e rurais. }\end{array}$ \\
\hline
\end{tabular}

Fonte: Elaborado pelas pesquisadoras, 2017.

Nos cursos de Engenharia, destacamos o Quadro 5:

Quadro 5: disciplinas dos Curso de Engenharia relacionadas à Ambientalização Curricular.

\begin{tabular}{|l|l|}
\hline $\begin{array}{l}\text { Engenharia } \\
\text { Civil }\end{array}$ & $\begin{array}{l}\checkmark \text { Engenharia Ambiental } \\
\text { Conceitos ambientais. Estrutura, funcionamento e dinâmica de ecosistemas. } \\
\text { O contexto mundial. Economia ecológica. A variável ambiental nas } \\
\text { organizações e na concepção de materiais e produtos. Prevenção de } \\
\text { poluição. Gestão ambiental (ISO 14001). Legislação e Conservação dos } \\
\text { recursos naturais. }\end{array}$ \\
\hline $\begin{array}{l}\text { Engenharia de } \\
\text { Produção }\end{array}$ & $\begin{array}{l}\text { Fontes de poluição sólidas, líquidas e gasosas da indústria. Formas de } \\
\text { tratamento dos efluentes. Diagnóstico. Parâmetros de medida. Modelos de } \\
\text { projeções. Resíduos. }\end{array}$ \\
\hline $\begin{array}{l}\text { Engenharia } \\
\text { Elétrica }\end{array}$ & $\begin{array}{l}\text { Noções gerais de ecologia. Noções gerais de ecossistemas. Ciclos do Ambiente } \\
\text { biogeoquímicos. Engenharia e meio ambiente. Educação Ambiental. Poluição } \\
\text { e degradação ambiental: poluição atmosférica, poluição hídrica, poluição dos } \\
\text { solos e contaminação radioativa. Planejamento ambiental, estudos } \\
\text { ambientais e Legislação. Sistemas de gestão ambiental. }\end{array}$ \\
\hline $\begin{array}{l}\text { Engenharia } \\
\text { Mecânica }\end{array}$ & $\begin{array}{l}\text { Engenharia e meio ambiente. Noções gerais de ecologia. Noçães gerais de } \\
\text { ecossistemas. Ciclos biogeoquímicos. Meio ambiente: poluição e degradação } \\
\text { ambiental, poluição atmosférica, uso múltiplo das águas, poluição dos solos, } \\
\text { contaminação radioativa. Planejamento ambiental, estudos ambientais. } \\
\text { Legislação. Fiscalização. Sistemas de gestão ambiental. }\end{array}$ \\
\hline
\end{tabular}

Fonte: Elaborado pelas pesquisadoras, 2017.

Esses cursos destacam assuntos pertinentes à relação homem/sociedade e natureza e caracterizam-se pelas discussões em torno da poluição quando envolve a complexidade ambiental da região Serrana de Santa Catarina. De modo geral, os temas abordados referem-se aos conteúdos que tratam da realidade ambiental como um todo abrindo possibilidades de estudos e projetos interdisciplinares entre os cursos de engenharia e os problemas ambientais do município. 
Junto aos cursos de engenharia, destacamos os tecnológicos que abordam a educação ambiental e que podem desenvolver projetos intercursos na Universidade, conforme demonstrado o Quadro 6.

Quadro 6: disciplinas dos Cursos de Tecnólogos relacionados à Ambientalização Curricular.

\begin{tabular}{|l|l|}
\hline $\begin{array}{l}\text { Tecnologia em Automação } \\
\text { Industrial }\end{array}$ & $\begin{array}{l}\checkmark \text { Gestão da Qualidade e Meio Ambiente } \\
\text { Globalização, qualidade e sustentabilidade. Princípios e } \\
\text { conceitos da qualidade - evolução do conceito. Teoria de } \\
\text { sistemas. Normalização. Sistemas de gestão da qualidade - } \\
\text { introdução, interpretação dos requisitos. Família NBR ISO } \\
14000 \text { - sistemas de gestão na qualidade ambiental - } \\
\text { introdução, interpretação dos requisitos. Implantação dos } \\
\text { sistemas de gestão da qualidade, gestão ambiental e seus } \\
\text { instrumentos. Sistematização de processos e métodos. } \\
\text { Instrumentos para avaliação de aspectos e impactos } \\
\text { ambientais. Aspectos da gestão de passivos ambientais. }\end{array}$ \\
\hline $\begin{array}{l}\text { Tecnologia em Fabricação } \\
\text { Mecânica }\end{array}$ & $\begin{array}{l}\text { Grincípios de gestão no desenvolvimento sustentável. } \\
\text { Relações produtivas e sócio-ambientais. }\end{array}$ \\
\hline
\end{tabular}

Fonte: Elaborado pelas pesquisadoras, 2017.

A complexidade da questão ambiental demanda que se cultivem projetos e discussões como parte integrante da formação de todas as categorias de profissionais. A inclusão das disciplinas de Gestão da Qualidade e Meio Ambiente e de Gestão Ambiental nos planos de ensino demonstram o comprometimento do curso de graduação, dos professores e dos alunos no processo de ensino-aprendizagem sustentável. A disciplina de gestão ambiental colabora, inclusive, com a formação dos profissionais na medida em que assumem nas organizações educacionais ou empresariais a busca da ecoeficiência, o que motiva a opinião pública, os consumidores e os segmentos da sociedade, que se encontram cada vez mais sensíveis aos esforços em prol da preservação ambiental (BRANDALISE et al.,2017). Essa disciplina então poderia estar inserida em outros cursos ou mesmo ser oferecida como optativa para todas as graduações.

Nos cursos de História, Geografia e Química, conforme Quadro 7, observamos que o curso de Geografia dispõe de três disciplinas centradas na Geologia, Geografia da População, Políticas Públicas e Meio Ambiente. O que se percebe que nenhuma das ementas contempla a questão do Aquífero Guarani ou a preservação dos recursos hídricos importantes para o contexto da cidade. Podemos perceber que a temática ambiental nesse curso é bem mais ampla no que diz respeito às questões pertinentes ao espaço geográfico humano e políticas públicas. Os conteúdos do curso de Geografia que destacamos nas ementas abrangem características da ambientalização curricular, sobretudo nas questões referentes à espacialidade $e$ à territorialidade, categorias que mostram as relações entre o homem e a natureza. Para Carvalho et al. (2016) é fundamental a 
[...] presença de disciplinas ambientalizadas na formação inicial do aluno universitário e a oportunidade que estas representam para discussão das questões socioambientais na educação superior. Desse modo, esta estratégia de ambientalização curricular representa uma aposta na formação dos futuros profissionais, no sentido de propiciar atitudes sustentáveis e comportamentos pró-ambientais, como o consumo responsável e a redução dos impactos negativos ao ambiente, nos projetos com os quais estiverem envolvidos, entre outras ações ambientalmente responsáveis.

Quadro 7:Disciplinas do Curso de História, Geografia e Química relacionadas à Ambientalização Curricular

\begin{tabular}{|l|c|}
\hline \multirow{5}{*}{ Geografia } & $\begin{array}{c}\checkmark \text { Geologia } \\
\text { Rochas ígneas, sedimentares e metamórficas. Tempo geológico } \\
\text { minerais. Placas tectônicas. Terremotos. Intemperismo. Recursos } \\
\text { minerais e hídricos. Geologia e meio ambiente. Mapas e perfis } \\
\text { geológicos. Geologia do Brasil. Atividades de campo. } \\
\checkmark \quad \text { Geografia da População } \\
\text { Corpo e etnodemografia. População e meio ambiente. Longevidade } \\
\text { e cadeia etária atual. Família. Engenharia genética e os novos } \\
\text { processos de fecundação e reprodução. Novas pesquisas } \\
\text { demográficas e o movimento social. Prática de pesquisa. }\end{array}$ \\
& $\begin{array}{l}\checkmark \quad \text { Políticas Públicas e Meio Ambiente } \\
\text { Introdução à questão ambiental. Gestão pública do meio ambiente. } \\
\text { Gestão ambiental urbana. }\end{array}$ \\
\hline História & $\begin{array}{l}\checkmark \quad \text { História Ambiental } \\
\text { Campo da pesquisa em História Ambiental. Métodos e fontes em } \\
\text { História Ambiental. Estudos ambientais e estudos históricos: } \\
\text { abordagens interdisciplinares. História Ambiental na sala de aula. } \\
\text { Abordagens didático-pedagógicas. }\end{array}$ \\
\hline Química & $\begin{array}{l}\checkmark \text { Ética Profissional } \\
\text { Noções de Ética Geral. Ética no Mundo Contemporâneo: Meio } \\
\text { Ambiente e Pesquisa. Ética profissional no âmbito da docência e } \\
\text { dos demais profissionais da química: direitos e deveres. }\end{array}$ \\
\hline
\end{tabular}

Fonte: Elaborado pelas pesquisadoras, 2017.

No curso de História, a temática ambiental está presente na disciplina "História ambiental", na qual os conteúdos estão relacionados ao contexto histórico dos estudos ambientais. No curso de Química a disciplina que trabalha a questão ambiental é a Ética Profissional e entre os eixos destacados temos o "Meio Ambiente e Pesquisa". Aqui não fica claro o objetivo da disciplina. Mas, quando trabalha a "Noções de Ética Geral" convém dar destaque à ética ambiental centrada na poluição em geral, poluentes tóxicos na água principalmente aqueles ligados à indústria química que contaminam os 
aquíferos. O trabalho educativo do curso de química poderia evidenciar a preservação dos ecossistemas e os impactos ambientais causados pela contaminação dos agentes químicos na natureza. Evidenciamos então cinco disciplinas nessas licenciaturas que poderiam se relacionar de forma interdisciplinar de modo a integrá-las na práxis do conhecimento.

Não é uma adjetivação da EA, mas sim, uma forma possível de integrá-la na relação entre a práxis e o conhecimento. De caráter transformador e emancipatório, é aquela que está conectada com os sentidos e os valores do ser-humano, oriundos dos experimentos sensoriais e significativos baseados em concepções individuais e coletivas, vivenciadas e construídas durante a história de vida de cada um. Ainda, [...] pretende resgatar no ente humano um pertencimento dialético ao outro e ao meio ambiente, na intenção de estabelecer um vínculo de cuidado com estes e consigo mesmo, [...] proporcionando um saber-agir em prol à qualidade de vida planetária (MOTA, 2016, p. 40-1)

Essa qualidade de vida também pode ser estendida aos cursos de cursos de Psicologia, Pedagogia e Serviço Social para identificar possíveis diálogos interdisciplinares, pois nas ementas aparecem eixos temáticos complementares, como políticas públicas e saúde e meio ambiente (Quadro 8):

Quadro 8: Disciplinas dos Cursos de Psicologia, Pedagogia e Serviço Social relacionados à Ambientalização Curricular

\begin{tabular}{|l|l|}
\hline $\begin{array}{l}\text { Formação de } \\
\text { Professor de } \\
\text { Psicologia - } \\
\text { Curso } \\
\text { Complementar }\end{array}$ & $\begin{array}{l}\checkmark \quad \text { Estrutura da Educação e Políticas Públicas } \\
\text { Política educacional no Brasil. Fundamentos legais, técnicos e } \\
\text { administrativos da Educação Básica. Professor da Educação Básica e } \\
\text { legislação vigente. Políticas de Educação Ambiental. Educação em } \\
\text { Direitos Humanos. } \\
\checkmark \text { Saúde e Meio Ambiente } \\
\text { Ecologia. Natureza e meio ambiente. Saúde e ambiente no } \\
\text { desenvolvimento de municípios saudáveis. Saúde coletiva e qualidade } \\
\text { de vida. Saneamento básico e ambiental. }\end{array}$ \\
\hline Pedagogia - & $\begin{array}{l}\checkmark \quad \text { Saúde e Meio Ambiente } \\
\text { Ecologia. Natureza e meio ambiente. Saúde e ambiente no } \\
\text { desenvolvimento de municípios saudáveis. Saúde coletiva e qualidade } \\
\text { de vida. Saneamento básico e ambiental. }\end{array}$ \\
\hline $\begin{array}{l}\checkmark \quad \text { Serviço Social: Política Agrária, Habitacional e Meio } \\
\text { Bachiço Social - }-\end{array}$ & $\begin{array}{l}\text { Ambiente } \\
\text { Política agrária no Brasil. Debate sobre a reforma agrária nos anos 80- } \\
\text { 90. Movimentos sociais no campo. Habitação: política habitacional } \\
\text { brasileira. Serviço Social e meio ambiente. Intervenções, demandas e } \\
\text { respostas profissionais. }\end{array}$ \\
\hline
\end{tabular}

Fonte: Elaborado pelas pesquisadoras, elaborado pelas autoras, 2017. 
Esses três cursos evidenciam possibilidades de agrupamentos de projetos interdisciplinares e intercursos de modo a discutir a realidade social vivenciada na cidade e região. Meio Ambiente é uma categoria que se repete nas ementas, esse é um ponto para se estabelecer relações entre o meio ambiente e as formas de vida que na região se estabelecem, avaliando fatores que implicam a qualidade de vida humana.

Assim, no estudo preliminar realizado para levantamento dos cursos nos quais disciplinas e ementas apresentam indícios de Ambientalização Curricular encontramos 18 cursos, e observamos que 15 outros não apresentam ainda essa associação. Para Guerra (2014, p. 136), a presença da dimensão ambiental na educação superior requer alguns requisitos:

- exige formação adequada dos docentes e funcionários na atualização para desenvolver um trabalho baseado na interdisciplinaridade.

- associa-se à onda do enfoque científico das disciplinas que tem sido influenciada por um conjunto de fatores sociais visando à modernização, mas que raramente veio acompanhada de reflexões sobre o impacto da ciência e os riscos provenientes da tecnologia na sociedade.

- ambiciona a institucionalização da questão ambiental em todos os níveis e modalidades de ação da universidade o que tem mostrado um desafio surpreendente, lançando atribuições sobre os mais diversos quadrantes das atividades, das práticas e políticas acadêmicas: ensino, gestão, pesquisa e extensão.

- implica que os indivíduos no âmbito universitário adquiram a capacidade de compreender e avaliar os aspectos sociais, ambientais, políticos e éticos relacionados às inovações científicas e às aplicações tecnológicas na sociedade.

- compreende a dimensão da sustentabilidade inserida nos diversos espaços universitários, pois, inclusive, no caso da forma da gestão do espaço, se manifestam reflexos na formação de futuros profissionais em todos os campos do conhecimento.

O exposto permitiu detectar o caminho até então percorrido por nossa universidade para a inserção do tema ambiental nos processos de ensino, pesquisa, extensão e gestão compondo sua política ambiental. $\mathrm{Na}$ sociedade como na universidade a educação ambiental diz respeito a um processo de longo prazo, inclui debates, reforma de pensamento, dilemas da participação de vários processos nas questões de meio ambiente. 


\section{Considerações finais}

Compreendemos a importância se trabalhar a EA na educação de nível superior e de processos de formação voltados a educadores ambientais. Os professores, além da formação acadêmica pautada em conhecimentos específicos de sua área de formação, de caráter técnico e científico, necessitam compreender a educação para Inteireza como caminho propício à ambientalização curricular dos cursos de graduação. Torna-se urgente a realização de processos educacionais complementares direcionados para uma Educação da Inteireza do Ser (POZATTI, 2012) considerando que muitas intervenções humanas ainda ignoram a profundidade das variações ecológicas que produzem.

No século XXI convivemos, ainda, com a dicotomia entre projetos humanos e econômicos, em desarmonia o ser humano deixa de discutir questões básicas da vida: seu lugar no mundo, sua responsabilidade e seu futuro comum. A Educação para Inteireza surge como possibilidade para a busca de um pensamento organizador capaz de respeitar a inseparabilidade entre qualquer contexto gerando a necessidade de uma ampliação no olhar na direção das relações, inter-relações e implicações mútuas entre ser humano e a vida no planeta.

Nesse sentido, diante do estudo preliminar realizado sobre as ementas das disciplinas, podemos considerar que a Ambientalização Curricular ainda está pautada em soluções impostas por leis e se revela pouco expressiva nos documentos curriculares da UNIPLAC. Dos 33 cursos de graduação analisados, apenas 18 contêm indícios de ambientalização. A difusão de um novo compromisso para com o meio ambiente passa por normas de conduta individuais, só se impõe pela formação de um campo específico de educação ambiental, e com a reorganização de ementas, disciplinas, cursos e formação de educadores ambientais. Considerando que as partes e os efeitos, têm consequências para o todo, pois alimentam as suas próprias causas, seguimos as orientações de Morin (2010, p.112) sobre o paradigma da complexidade:

[...] eu não posso tirar, nem pretendo tirar do meu bolso um paradigma da complexidade. Um paradigma [...] é no fundo, o produto de todo um desenvolvimento cultural, histórico e civilizacional. O paradigma da complexidade surgirá do conjunto de novas concepções, de novas visões, de novas descobertas e de novas reflexões que vão conciliar-se e juntarse. 
"processo de ambientalização" que, para além do discurso, junte essa nova reflexão à prática institucional.

\section{Agradecimentos}

À FAPESC pelo apoio financeiro à pesquisa do Programa Universal, intitulado "Ambientalização e Sustentabilidade na Educação Superior: subsídios às políticas institucionais em Santa Catarina".

\section{Referências}

ANDRADE, I.C.F. A inteireza do ser: uma perspectiva transdisciplinar na autoformação de educadores / Tese, PUCRS, Porto Alegre, 2011. $213 \mathrm{f}$.

ANDRADE, I.C.F.; PORTAL, L.L.F. A inteireza do ser: uma perspectiva transdisciplinar na autoformação de educadores. 2012. Disponível em: $<$ http://www.ucs.br/etc/conferencias/index.php/anpedsul/9anpedsul/paper/viewF ile/1133/451>

ANDRADE, I.C.F.; PORTAL, L.L.F. A inteireza do ser: uma perspectiva transdisciplinar na autoformação de educadores. Editora ICEP: São José/SC., 2015.

ANDRADE, I.C.F., ARRUDA, M.P.; PORTAL, L.L.F. Educação para inteireza: um caminho para a reforma da educação e do pensamento. Impulso, Piracicaba - 26(65), 43-49, jan.-abr. 2016. Disponível em: $<$ https://www.metodista.br/revistas/revistasunimep/index.php/impulso/article/view/2427/1774>

ANDRADE, I.C.F.; PORTAL, L.L.F. Autoformação de educadores numa perspectiva de uma formação continuada para a inteireza: um interesse do centro universitário municipal de São José. TERCEIRO INCLUÍDO-ISSN 2237079X DOI: 10.5216 NUPEAT-IESA-UFG, v.2, n.2, jul./dez., 2012, p. 123-147, Artigo 33.

BEHRENS, M.A. Paradigmas da Complexidade: Metodologia de Projetos, Contratos Didáticos e Portfólios. Petrópolis,RJ: Vozes, 2006.

BRANDALISE, L.T.; BERTOLINI, G.R.F.; HOSS, O.; ROJO, C. A. Educação e gestão ambiental: sustentabilidade em ambientes competitivos. 2.ed. Cascavel/PR: DRHS, 2017.

BRASIL, MEC: Ministério da Educação. Resolução no 2, de 15 de junho de 2012. Estabelece as Diretrizes Curriculares Nacionais para a Educação Ambiental.

em: $<$ http://conferenciainfanto.mec.gov.br/images/conteudo/iv-cnijma/diretrizes.pdf> Acesso em: mar. 2018.

CAPRA, F. O Ponto de Mutação: A Ciência, a Sociedade e a Cultura emergente. $23^{\underline{a}}$ ed. Trad. Álvaro Cabral. São Paulo, SP: Editora PensamentoCultrix Ltda, 2002.

revista brasileira educação ambiental 
CARVALHO, I.C.M., WACHHOLZ, C.B.; SILVA, A.N. Ambientalização curricular: uma análise a partir das disciplinas ambientalmente orientadas na Pontifícia Universidade Católica do Rio Grande do Sul (PUCRS) Rev. Eletrônica Mestr. Educ. Ambient. E-ISSN 1517-1256, v. 33, n.2, p. 209-226, maio/ago., 2016. https://www.seer.furg.br/remea/article/viewFile/5684/3895.

CARVALHO, I.C.M.; TONIOL, R. Ambientalização, cultura e educação: diálogos, traduções e inteligibilidades possíveis desde um estudo antropológico da educação ambiental. Rev. eletrônica Mestr. Educ. Ambient. ISSN 15171256, v. especial, setembro de 2010,PP.28-39.

GODOY, A. Opinião, biopolítica, governamentalidade e controle: as armadilhas da ambientalização e seus muitos e estranhos funcionamentos. Revista Política \& Trabalho, v. 36, p. 239-256, 2012.

GONÇALVES-DIAS, S.L.F. et al. A inserção da temática ambiental em cursos de Administração: uma tipologia para (re) pensar a formação de administradores. Encontro Anual da Associação Nacional dos Cursos de PósGraduação em Administração. 30. Anais eletrônicos... Salvador: ANPAD, 2006

GUERRA, A.F.S. et al. A temática ambiental e a sustentabilidade nos cursos de graduação da UNIVALI: caminhos para a ambientalização curricular na universidade. Revista Eletrônica do Mestrado em Educação Ambiental, Rio Grande, v. 1, p.121-134, maio 2014. Disponível em: <https://www.seer.furg.br/remea/article/view/4435>. Acesso em: 18 jan. 2017

JAPIASSU, H. O sonho transdisciplinar e as razões da Filosofia. Rio de Janeiro: Imago, 2006.

KITZMANN, D.I.S.; ASMUS, M.L. Ambientalização Sistêmica - do currículo ao socioambiente. Currículo sem fronteiras, v. 12, n. 1, p. 269 - 290, 2012.

KITZMANN, D. Ambientalização de Espaços Educativos: aproximações metodológicas. Rev. Eletrônica Mestr. Educ. Ambient., v. 18, p. 553-574, 2007.

LEFF, E. Saber Ambiental. Petrópolis-RJ: Vozes, 2001.

MARTINELLI, M. Aulas de Transformação: o programa de educação em valores humanos. São Paulo: Petrópolis, 1996.

MORAES, M.C. O paradigma educacional emergente. Campinas: Papirus, 1998.

MORIN, E. Os sete saberes necessários à educação do futuro. 8 ed. São Paulo: Cortez; Brasília: UNESCO, 2010.

MORIN, E. Complexidade e transdisciplinaridade: a reforma da universidade e do ensino fundamental. Natal: EDUFRN, 2003.

MORIN, E. O Método 5 - A humanidade da humanidade: a identidade humana. Porto Alegre: Sulina, 2004.

MORIN, E. Ciência com consciência. Rio de Janeiro: Bertrand Brasil, 2013. 
MORIN, E. Introdução ao pensamento complexo. 3. ed. Porto Alegre: Sulina, 2010.

MOTA, J.C. A Educação Ambiental Estética como uma ferramenta à (re)significação do ser-sensível. In: IV Seminário Interfaces Pedagógicas: Licenciaturas em diálogo, 2016, Rio Grande. Ebook IV Seminário Interfaces Pedagógicas: Licenciaturas em diálogo. Rio Grande: Pluscom, 2016. v. 4. p. 38- 41.

NICOLESCU, B. Manifesto da transdisciplinaridade. Brasília: UNESCO, 2000.

PORTAL, L.L.F.(et.al.) Uma teoria do tudo: contribuições para uma condição singular de ser. Revista Humanidades, v.19, N 1, p.40-45, jan./jun., 2004.

PORTAL, L.L.F. Espiritualidade: uma dimensão essencial na experiência significativa da vida. In: TEIXEIRA, E.F.B.; MÜLLER, M.C.; SILVA, J.D.T. Espiritualidade e qualidade de vida. Porto Alegre: Edipurcs, 2004.

PORTAL, L.L.F. O sentido da existência humana: um olhar para cima na aventura do encontro interior. In: ENRICONE, D. (Org.). A docência na educação superior: sete olhares. Porto Alegre: Evangraf, 2006. p. 45-58.

POZATTI, ML. Educação para a Inteireza do Ser: uma caminhada. Educ. Real., Porto Alegre, v. 37, n. 1, p. 143-159, jan./abr. 2012. Disponível em: $<$ http://seer.ufrgs.br/index.php/educacaoerealidade/article/view/21801/16019> acesso em 15/05/2016.

SANTOS, T.A. et al. $\mathbf{O}$ valor das pequenas coisas: a difícil aprendizagem na prática da gestão ambiental por acadêmicos do curso de Administração. In: ENCONTRO ANUAL DA ASSOCIAÇÃO NACIONAL DOS CURSOS DE PÓSGRADUAÇÃO EM ADMINISTRAÇÃO, 24., 2000, Florianópolis. Anais eletrônicos... Florianópolis: ANPAD, 2000.

TESCAROLO, R.; DARÓS, L. Aprendizagem e conhecimento: conexões planetárias. Revista Diálogo Educacional. Curitiba: Champagnat, v.7, n.20, 2007.

WILBER, K. Uma teoria de tudo: uma visão integral para os negócios, a política, a ciência e a espiritualidade. São Paulo: Cultrix, Amaná-Key, 2007.

ZUIN, V.G.; FREITAS, D. A utilização de temas controversos: estudo de caso na formação inicial de licenciandos numa abordagem CTSA. Ciência \& Ensino (UNICAMP), v.1, n.2, 2007. Disponível em $<$ http://www.ige.unicamp.br/ojs/index.php/cienciaeensino/article /viewFile/136/129>. Acesso em 30 de abril de 2009. 